\title{
Morfologia polínica de espécies epífitas de Cactaceae Juss. do Rio Grande do Sul, Brasil
}

\author{
Rodrigo Rodrigues Cancelli, Ivan Cabral Menezes \& Paulo Alves Souza
}

Universidade Federal do Rio Grande do Sul, Instituto de Geociências, Laboratório de Palinologia Marleni Marques Toigo. Av. Bento Gonçalves, 9.500, CEP 91.540-000, Porto Alegre, Brasil. rodrigocancelli@hotmail.com.br, ivancabralmenezes@gmail.com, paulo.alves.souza@ufrgs.br.

RESUMO - Neste trabalho é apresentado o estudo sobre a morfologia polínica de 11 espécies da família Cactaceae, com hábito epífito, ocorrentes no Rio Grande do Sul, extremo sul do Brasil, com descrições, medidas, fotomicrografias, bem como informações ecológicas e biogeográficas. Os grãos de pólen possuem tamanhos variáveis (médios, grandes e gigantes), com formas prolato-esferoidais a prolatos; aberturas 3-colpados (Lepismium cruciforme (Vell.) Miq. e Rhipsalis cereuscula Haw.) e 6-colpados (demais espécies); exina tectada, com diminutos grânulos e perfurações; colpos cobertos por fina membrana granulada em todas as espécies, exceto Epiphyllum phyllanthus (L.) Haw.; ocorre heteromorfismo nas aberturas de L. houlletianum (Lem.) Barthlott, L. warmingianum (K. Schum.) Barthlott e Rhipsalis campos-portoana Loefgr. Os resultados palinológicos indicam dois padrões morfológicos nos táxons estudados: o primeiro (I) é relacionado aos grãos de pólen com abertura 3-colpadas e o segundo (II) aos de abertura 6-colpados.

Palavras-chave: palinologia, tipos polínicos, palinotaxonomia

\begin{abstract}
Pollen morphology of epiphytic species of the Cactaceae Juss. from Rio Grande do Sul, Brazil. In this paper, we studied the pollen morphology of 11 species of epiphytic Cactaceae family in Rio Grande do Sul, southern Brazil. We provide descriptions, measurements, photomicrographs, as well as information on ecology and biogeography. The pollen grains are variable in size (medium, large and giant) with prolate-spheroidal to prolate forms; 3-colpate aperture (Lepismium cruciforme (Vell.) Miq. and Rhipsalis cereuscula Haw.) and 6-colpate (remaining species); exine with tectum and small granulate texture and perforations; except for Epiphyllum phyllanthus (L.) Haw, colpi are covered by thin granulate membrane; heteromorphism in the apertures of L. houlletianum (Lem.) Barthlott, L. warmingianum (K. Schum.) Barthlott and Rhipsalis campos-portoana Loefgr was observed. Results indicate two morphological patterns in the study taxa: the first (I) is related to pollen grains with 3-colpate aperture and second (II) with 6-colpate aperture.
\end{abstract}

Keywords: palynology, pollen type palynotaxonomy

\section{INTRODUÇÃO}

A família Cactaceae Juss. possui cerca de 1.300 espécies e é endêmica no continente americano, distribuindo-se desde o Canadá até a Argentina, com exceção de Rhipsalis bacífera (Sol.) Stearn, que é encontrada no Velho Mundo. A família é representada por espécies arborescentes, arbustivas, trepadeiras ou de hábito epífito (Barthlott \& Hunt 1993).

No Brasil, são descritas cerca de 220 espécies da família com hábito epífito, as quais são principalmente adaptadas nas florestas tropicais e subtropicais úmidas. A maioria pertence à subfamília Cactoideae e às tribos Hylocereeae e Rhipsalideae (Barthlott 1983).

Os principais estudos botânicos para seus representantes epífitos no Brasil foram realizados por Loefgren (1915, 1917) e Ritter (1979), além de trabalhos regionais: Lombardi (1991, 1995) para o estado de São Paulo, Freitas (1992) para o Rio de Janeiro, Geraldino et al. (2010) para o Paraná, Scheinvar (1985) para Santa Catarina.

Os registros de cactáceas com hábito epífito no Rio Grande do Sul (RS) fazem parte de levantamentos florísticos, fitossociológicos e estudos com epífitos vasculares. As contribuições pioneiras de Rambo (1951, 1954a, 1954b, 1956a, 1956b, 1961) sobre as florestas no Rio Grande do Sul, Brack et al. (1985) e Rogalski \& Zanin (2003), sobre a mata pluvial do Alto Uruguai, Waechter (1986, 1998), Gonçalves \& Waechter (2003) sobre epífitos vasculares na Planície Costeira, e Giongo \& Waechter (2004) sobre epífitos na Depressão Central compõem estes levantamentos, conforme sintetizado por Bauer \& Waechter (2006) e Carneiro et al. (2016).

Estudos de caracterização da morfologia polínica podem contribuir como subsídios na caracterização das famílias botânicas (Nowicke \& Skvarla 1979). Nowicke (1975) estudou os grãos de pólen de 12 espécies de Cactáceas pertencentes à subfamília Opuntoideae, constatando caracteres que são compartilhados na maioria das espécies: teto microequinado-perfurado, observados nos grãos de pólen com abertura do tipo 3-colpados, pantocolpados e pantoporados. A partir do estudo de 600 espécies de Cactaceae das Américas, Leuenberger (1976) identificou diferentes tipos de aberturas: grãos de pólen 3-colpados, 6 a 12-colpados (pantocolpados), 12-porados e as que apresentaram mais de 12 poros (pantoporados). 
Lattar \& Cuadrado (2010) propuseram tipos polínicos com base na forma e tipo das aberturas para os gêneros de cactáceas Cereus Mill., Cleistocactus Lem., Denmoza Britton \& Rose, Echinopsis Zucc. e Monvillea Britton \& Rose, também ocorrentes em território argentino.

Para a região nordeste do Brasil, dispõe-se da contribuição de Santos et al. (1997), que descreveram 19 espécies de cactáceas, tendo sido constatados cinco grupos polínicos, com base em distintos padrões morfológicos (tamanho, textura da exina, tipo e posição das aberturas).

No Rio Grande do Sul, foram descritas 15 espécies pertencentes a cinco gêneros (Echinopsis, Gymnocalycium Pfeiff. ex Mittler, Notocactus Berger, Frailea Britton \& Rose e Opuntia L.) de cactáceas terrícolas, das regiões do Pampa e Planície Costeira (Schlindwein 1995), com a identificação de dois grupos morfológicos, fundamentada, principalmente, nos diferentes tipos de aberturas. Em Bauermann et al. (2013) é descrita a morfologia polínica de Opuntia ficus-indica Mill. que tem sua distribuição territorial em quase todo o litoral brasileiro.

Contudo, dados a respeito da morfologia polínica de espécies de Cactaceae com hábito epífito são escassos no RS. Desta forma, este trabalho objetiva ampliar o conhecimento sobre a morfologia polínica de 11 espécies pertencentes a quatro gêneros da família, constituindo o primeiro relato desta natureza para o Estado. Os resultados são potencialmente úteis nas identificações palinológicas de material disperso e aqueles recuperados em sedimentos quaternários.

\section{MATERIAL E MÉTODOS}

Os espécimes analisados são provenientes de exsicatas de 11 espécies da família Cactaceae depositadas no ICN (Herbário do Instituto de Biociências da Universidade Federal do Rio Grande do Sul): Epiphyllum phyllanthus (L.) Haw. (ICN-132200); Hatiora rosea (Lagerh.) Barthlott (ICN-132264); Lepismium cruciforme (Vell.) Miq. (ICN-122225); L. houlletianum (Lem.) Barthlott (ICN-184874); L. lumbricoides (Lem.) Barthlott (ICN132217); L. warmingianum (K. Schum.) Barthlott (ICN-143792); Rhipsalis campos-portoana Loefgr. (ICN-122266); $R$. cereuscula Haw. (ICN-124903); $R$. floccosa Salm-Dyck ex Pfeiff. (ICN-132210); R. paradoxa (Salm-Dyck ex Pfeiff.) Salm-Dyck (ICN-132221) e $R$. teres (Vell.) Steud (ICN-132204). Das exsicatas foram selecionadas anteras dos espécimes herborizados para o processamento palinológico. Para cada espécie, retirou-se pólen de pelo menos cinco flores de capítulos diferentes, com propósito de homogeneizar variações nas dimensões dos grãos de pólen, conforme orienta Salgado-Labouriau (1973).

A recuperação do material polínico foi realizada no Laboratório de Palinologia Marleni Marques Toigo do Instituto de Geociências da Universidade Federal do Rio Grande do Sul utilizando-se o método de acetólise descrito por Erdtman (1952). Para cada espécie, foram montadas quatro lâminas permanentes em Entellan, as quais estão depositadas no mesmo laboratório sob a codificação "MPPr", como parte do acervo de referência para estudos do Quaternário (Souza et al., 2009).

A análise da morfologia polínica, incluindo medidas (tomadas em até sete dias após a acetólise), foi realizada em microscópio óptico Olympus BX-51, sendo mensurados, aleatoriamente, 25 grãos de pólen para a determinação do diâmetro polar (P), diâmetro equatorial (E), espessura da exina e tamanho dos colpos, representadas pelas médias aritméticas acompanhadas do menor e maior valor. As descrições polínicas seguem a orientação de Barth \& Melhem (1988) e a terminologia utilizada é adaptada de Punt et al. (2007). Observações sobre a ecologia e a distribuição biogeográfica são apresentadas com base na literatura disponível.

Os grãos de pólen foram fotografados em microscopia óptica sob aumento de $1.000 \mathrm{x}$, com máquina digital Olympus C-3040, acoplado ao microscópio Olympus BX-51, sendo apresentadas fotomicrografias dos grãos em vista polar (VP) e equatorial (VE). Todas as imagens de microscopia óptica, bem o modelo hipotético proposto, foram tratadas no programa Corel Draw X5 e Corel Photopaint (cor, preenchimento do fundo e montagem das figuras e modelo), apresentadas seguindo a ordenação alfabética (gênero e espécie). Os nomes botânicos e autores correspondentes estão de acordo com a base de dado internacional (The International Plant Name Index 2016).

\section{RESULTADOS}

\section{Descrições morfológicas}

São apresentadas as descrições morfológicas polínicas das 11 espécies de cactáceas epífitas acompanhadas de informações ecológicas, assim como ilustrações dos grãos de pólen.

Os dados morfométricos das espécies descritas encontram-se na tabela 1 .

Epiphyllum phyllanthus (L.) Haw.

(Figs. 1-3)

Descrição polínica: grãos de pólen de tamanho muito grande; prolato-esferoidais; 6-colpados; exina tectadaperfurada, coberta por grânulos onde as diminutas perfurações são circundadas por sutil engrossamento dos grânulos da sua periferia.

Observações ecológicas: plantas epifíticas, semi-eretas ou pendentes. A espécie ocorre do Panamá ao Paraguai (Kimnach 1964). No RS, apresenta-se como epífito característico, com ocorrência nos biomas Mata Atlântica e Pampa, na Floresta Estacional Decidual e formações pioneiras (matas ciliares) do Alto e Médio rio Uruguai (Bauer \& Waechter 2006). 
Hatiora rosea (Lagerh.) Barthlott

(Figs. 4, 6)

Descrição polínica: grãos de pólen de tamanho muito grande; prolato-esferoidais; 6-colpados, colpos com membrana apertural granulada; exina tectada-perfurada coberta por grânulos distribuídos uniformemente.

Observações ecológicas: plantas epifíticas, semi-eretas ou pendentes de pequeno porte. A espécie ocorre nos estados do Paraná, Santa Catarina e na região nordeste do RS (Barthlott \& Taylor 1995), onde é encontrada nas florestas Ombrófila Densa e Ombrófila Mista (Bauer \& Waechter 2006).

\section{Lepismium cruciforme (Vell.) Miq.}

(Figs. 7, 8)

Descrição polínica: grãos de pólen de tamanho grande; prolato-esferoidal; 3-colpados, colpos grandes com membrana apertural granulada; exina tectada coberta por grânulos distribuídos uniformemente.

Observações ecológicas: plantas epifíticas ou rupícolas, reptantes a pendentes. A espécie é registrada na Argentina, Paraguai e, no Brasil, de Pernambuco até o RS (Barthlott \& Taylor 1995), onde ocorre em todas as formações florestais, exceto regiões de Savana e Savana Estépica (Bauer \& Waechter 2006).

Lepismium houlletianum (Lem.) Barthlott

(Figs. 9, 10)

Descrição polínica: grãos de pólen de tamanho médio a grande; prolato-esferoidais; 6-colpados (são observados em baixa frequência grãos 3-colpados), colpos curtos e estreitos; exina tectada coberta por diminutos grânulos distribuídos uniformemente.

Observações ecológicas: plantas epifíticas ou rupícolas, semi-eretas ou pendentes. A espécie ocorre na Argentina e no Brasil, de Minas Gerais até RS (Barthlott \& Taylor 1995), onde é registrada nas florestas Ombrófila Densa, Ombrófila Mista, Estacional Decidual, Estacional Semidecidual e Formações Pioneiras como matas ciliares e turfáceas (Bauer \& Waechter 2006).

Lepismium lumbricoides (Lem.) Barthlott

(Figs. 11, 12)

Descrição polínica: grãos de pólen de tamanho grande; prolato-esferoidais; 6-colpados, colpos com membrana apertural granulada; exina tectada-perfurada coberta por grânulos distribuídos uniformemente.

Observações ecológicas: plantas epifíticas, raramente rupícolas, reptantes ou pendentes. A espécie ocorre na Bolívia, Argentina, Uruguai, Paraguai e no Brasil, de São Paulo até o RS (Barthlott \& Taylor 1995). No RS, a espécie é registrada em todas as formações florestais, porém é rara na Floresta Ombrófila Densa (Bauer \& Waechter 2006).
Lepismium warmingianum (K. Schum.) Barthlott

(Figs. 13, 14)

Descrição polínica: grãos de pólen de tamanho grande; prolato-esferoidais; 6-colpados (são observados em baixa frequência grãos 3-colpados), colpos com membrana apertural granulada; exina tectada-perfurada coberta por grânulos distribuídos uniformemente.

Observações ecológicas: plantas epifíticas, raramente rupícolas, reptantes ou pendentes. A espécie ocorre na Argentina, Paraguai e no Brasil, de Minas Gerais ao RS (Barthlott \& Taylor 1995), onde é documentada nas florestas Ombrófila Densa, Ombrófila Mista, Estacional Decidual, Estacional Semidecidual, formações pioneiras (matas ciliares) e florestais nas regiões de Savana (Bauer \& Waechter 2006).

Rhipsalis campos-portoana Loefgr.

(Figs. 15, 16)

Descrição polínica: grãos de pólen de tamanho médio; prolato-esferoidais; 6-colpados (são observados em baixa frequência grãos 3-colpados), colpos com membrana apertural granulada; exina tectada-perfurada coberta por grânulos distribuídos uniformemente.

Observações ecológicas: plantas epifíticas ou rupícolas, pendentes. A espécie ocorre de Minas Gerais até o RS, onde é encontrada apenas na Floresta Ombrófila Densa (Bauer \& Waechter 2006).

Rhipsalis cereuscula Haw.

(Figs. 17, 18)

Descrição polínica: grãos de pólen de tamanho médio a grande; subprolato; 3-colpados, colpos com membrana apertural granulada; exina tectada-perfurada coberta por grânulos distribuídos uniformemente.

Observação: a espécie apresentou grãos de pólen mais frágeis ao processo de acetólise, evidenciando fragilidade ao método quando comparada com as demais espécies estudadas (Fig. 18).

Observações ecológicas: plantas epifíticas ou rupícolas, eretas ou pendentes. Ocorre na Bolívia, Argentina, Paraguai, Uruguai e, no Brasil, de Pernambuco ao RS (Barthlott \& Taylor 1995), encontrada nas florestas Estacional Decidual, Estacional Semidecidual e nas formações pioneiras (matas ciliares). A espécie é característica das matas junto às margens de rios e arroios, onde pode ser encontrada como epifítica quase ao nível do solo, indicando que nestes locais as plantas podem ser submersas nos períodos das cheias (Bauer \& Waechter 2006).

\section{Rhipsalis floccosa Salm-Dyck ex Pfeiff.}

(Figs. 19, 20)

Descrição polínica: grãos de pólen de tamanho médio a grande; subprolatos; 6-colpados, colpos com membrana apertural granulada; exina tectada-perfurada coberta por 
1

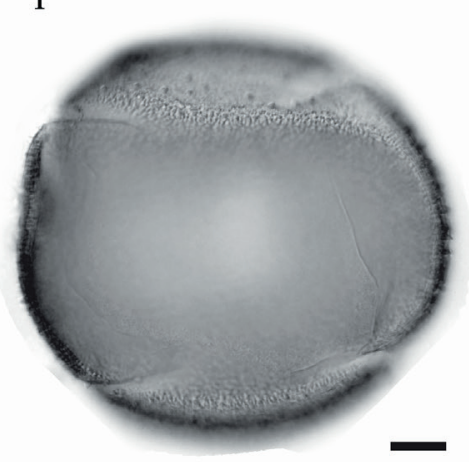

4

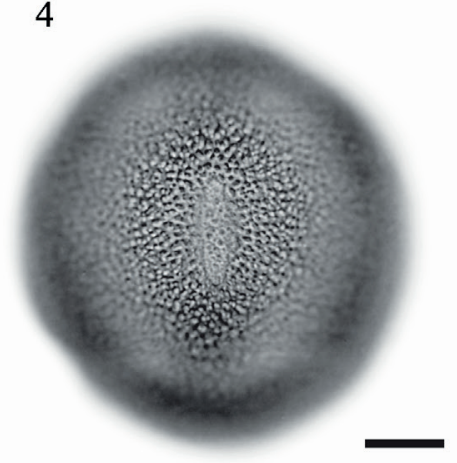

7

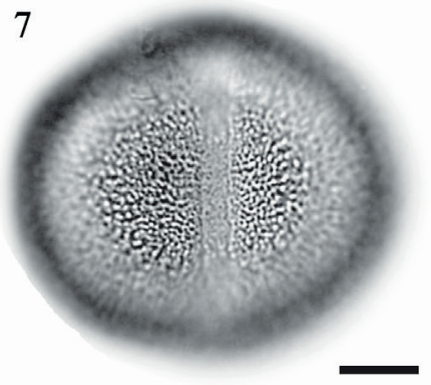

10

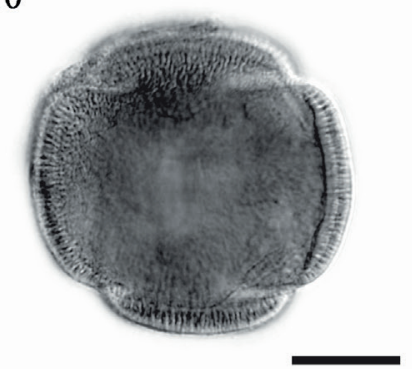

2

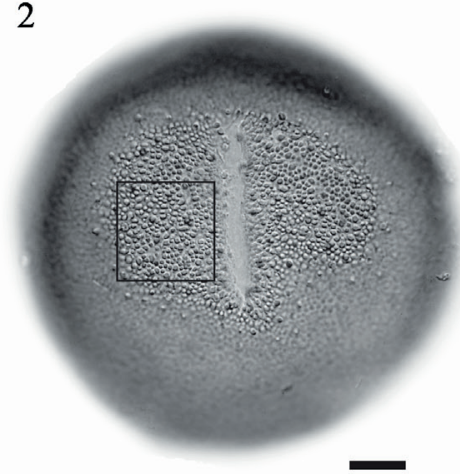

5

8

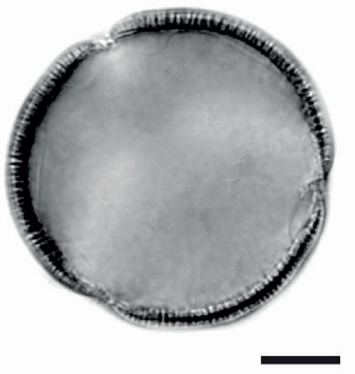

11

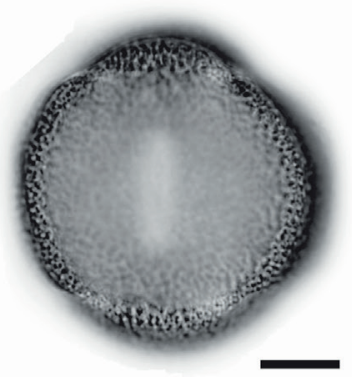

3
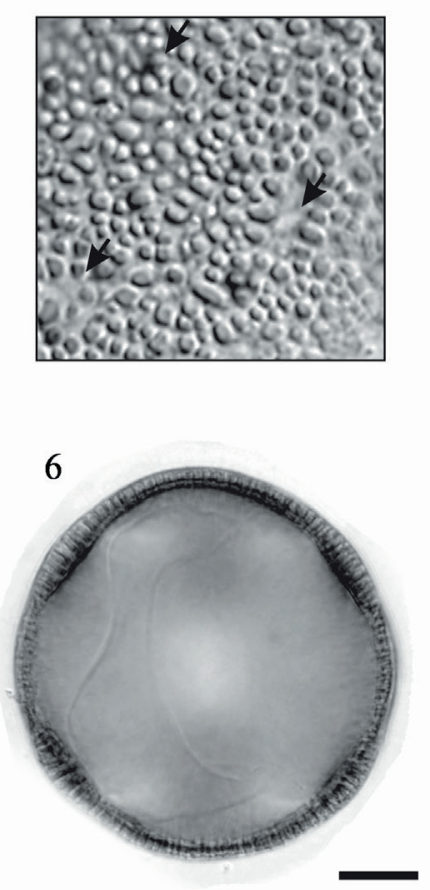

9

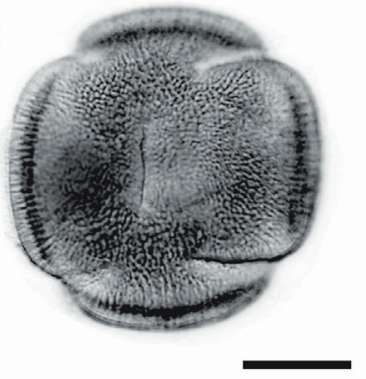

12

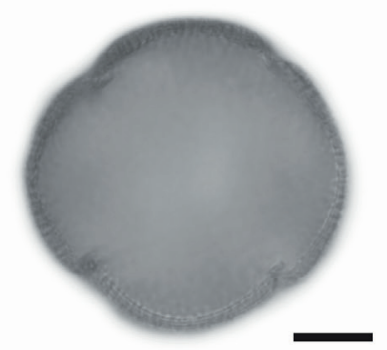

Figs. 1-12. Fotomicrografias de grãos de pólen da família Cactaceae. 1-3 Epiphyllum phyllanthus. 1. vista equatorial, corte óptico evidenciando a espessura da exina e aberturas; 2. superfície da exina e detalhe da abertura em colpo; 3. ampliação da superfície mostrando grânulos e perfurações no teto (vide seta); 4-6 Hatiora rósea. 4. vista equatorial, detalhe do colpo; 5. posicionamento das aberturas; 6. corte óptico evidenciando a espessura da exina e columelas; $\mathbf{7 , 8}$ Lepismium cruciforme. 7. vista equatorial, mostrando a abertura recoberta por diminutos grânulos; 8 . vista polar, corte óptico evidenciando a espessura da exina e columelas; 9, 10 L. houlletianum. 9. vista equatorial, detalhe do posicionamento das aberturas e superfície da exina; 10. corte óptico evidenciando a espessura da exina e columelas; 11, 12 L. lumbricoides. 11. vista equatorial, posicionamento das aberturas; 12. corte óptico evidenciando a espessura da exina e columelas. Barras $=20 \mu \mathrm{m}$. 
grânulos distribuídos uniformemente.

Observações ecológicas: epifíticas, semi-eretas, pendentes ou raramente reptantes. A espécie ocorre na Venezuela, Peru, Bolívia, Argentina, Paraguai e, no Brasil, de Pernambuco até o RS (Barthlott \& Taylor 1995), onde ocorre nas florestas Ombrófila Densa, Ombrófila Mista, Estacional Decidual, Semidecidual e formações pioneiras (matas turfosas e ciliares) (Bauer \& Waechter 2006).

Rhipsalis paradoxa (Salm-Dyck ex Pfeiff.) Salm-Dyck (Figs. 21, 22)

Descrição polínica: grãos de pólen de tamanho grande; prolato-esferoidais; 6-colpados, colpos com membrana apertural granulada; exina tectada-perfurada coberta por grânulos distribuídos uniformemente.

Observação: a espécie apresentou grãos de pólen mais frágeis ao processo de acetólise, evidenciando fragilidade ao método quando comparada com as demais espécies aqui estudadas (Fig. 22).

Observações ecológicas: plantas epifíticas ou rupícolas, reptantes ou pendentes. A espécie distribui-se de Pernambuco até o RS (Barthlott \& Taylor 1995), na Floresta Ombrófila Densa e nas formações pioneiras (matas turfosas) (Bauer \& Waechter 2006).

\section{Rhipsalis teres (Vell.) Steud}

(Figs. 23, 24)

Descrição polínica: grãos de pólen de tamanho grande; prolato-esferoidais; 6-colpados, colpos com membrana apertural granulada; exina tectada-perfurada coberta por grânulos distribuídos uniformemente.

Observações ecológicas: epifíticas, rupícolas ou terrícolas, semieretas ou pendentes. A espécie ocorre no Brasil de Minas Gerais ao RS (Barthlott \& Taylor 1995), onde é registrada em todas as formações florestais, exceto nas regiões de Savana e Savana Estépica (Bauer \& Waechter 2006).

\section{Padrões morfológicos}

Para as 11 espécies descritas, a análise da morfologia polínica permitiu a identificação de dois padrões morfológicos, com base no número e posicionamento das aberturas. O primeiro padrão (I) é relacionado aos grãos de pólen com aberturas 3-colpados (Lepismium cruciforme e Rhipsalis cereuscula) e o segundo (II) às aberturas do tipo 6-colpados (Epiphyllum phyllanthus; Hatiora rosea; Lepismium houlletianum; L. lumbricoides; L. warmingianum; Rhipsalis campos-portoana; R. floccosa; R. paradoxa e R. teres) (Fig. 25). Neste contexto, o padrão I foi verificado em grãos de pólen com tamanho grande não ultrapassando o intervalo de 50 a $100 \mu \mathrm{m}$, e os que incluem o padrão II podem variar de grãos de pólen médios, menores que $50 \mu \mathrm{m}$; grandes, de 50 a $100 \mu \mathrm{m}$ e muito grande, de 100 a $200 \mu \mathrm{m}$. Na figura 25 , é possível mostrar a relação das médias do tamanho dos grãos de pólen com o número de aberturas (3-colpados e 6-colpados). Em todos os grãos de pólen estudados os colpos são recobertos por membrana apertural granulada, exceto Epiphyllum phyllanthus (Figs. $1,2)$ e exina coberta por pequenos grânulos distribuídos uniformemente com pequenas variações sob microscopia óptica (análise LO). Observa-se, por vezes, o rompimento da membrana dos colpos (Figs. 17 e 21, por exemplo).

Neste trabalho foi apresentado um grão de pólen em plano transversal (Fig. 20), com propósito de mostrar a dificuldade na determinação do número e posicionamento das aberturas, os quais podem ser facilmente confundidos. Dentre os gêneros analisados não foram observados grãos de pólen com aberturas do tipo porado.

\section{DISCUSSÃO}

De modo geral, as cactáceas epífitas analisadas variam de tamanho, sendo reconhecidos grãos de pólen médios (Rhipsalis campos-portoana), médios a grandes (Lepismium houlletianum; R. cereuscula; R. floccosa), grandes (Lepismium cruciforme; L. lumbricoides; L. warmingianum; $R$. paradox; $R$. teres) e muito grandes (Epiphyllum phyllanthus; Hatiora rosea) (Tab. 1).

Aberturas do tipo 3-colpados e 6-colpados compõem os dois padrões morfológicos aqui estudados e podem ser relacionados aos tipos polínicos descritos por Cuadrado \& Garralla (2009). Aberturas do tipo 3-colpados ocorrem em Maihuenia patagonica Britton \& Rose e M. poeppigii Speg. e 6-pantocolpados para Pereskia aculeata Mill. Além disso, as autoras identificaram em outras espécies, diferentes tipos de aberturas, grãos de pólen pantocolpados com 9 até 14-colpados. Lattar \& Cuadrado (2010) propuseram dois tipos polínicos para cactáceas da Argentina para os gêneros Cereus, Cleistocactus, Denmoza e Echinopsis, com base, principalmente, na forma e aberturas (todos com abertura 3-colpados) e variação no tamanho.

Dois padrões também foram analisados com base em grãos de pólen de 14 espécies de cactáceas endêmicas do norte do Chile (Miesen et al. 2015): tipo periporado em Cumulopuntia sphaerica (C.F. Först.) E.F. Anderson, Maihueniopsis camachoi (Espinosa) F. Ritter, Tunilla soehrensii (Britton \& Rose) D.R. Hunt \& Iliff e 3-colpados em Echinopsis atacamensis (Phil.) H. Friedrich \& G.D. Rowley, E. coquimbana (Britton \& Rose) A.E. Hoffm., Haageocereus chilensis F. Ritter ex D.R. Hunt, Oreocereus hempelianus (Gürke) D.R. Hunt, O. leucotrichus (Phil.) Wagenkn., Copiapoa coquimbana (Karw. ex Rümpler) F. Ritter, Eriosyce aurata (Pfeiff.) Backeb., E. subgibbosa (Haw.) Katt., Eulychnia breviflora Phil., Browningia candelaris (Meyen) Britton \& Rose e Corryocactus brevistylus Britton \& Rose. Para Miesen et al. (2015), a distinção só é possível em nível taxonômico de gênero, com difícil resolução quando se trata da determinação em nível de espécie.

Santos et al. (1997) descreveram os grãos de pólen de 19 espécies de cactáceas ocorrentes na Bahia (Nordeste do Brasil), com a distinção de cinco grupos polínicos: (1) grãos 
13
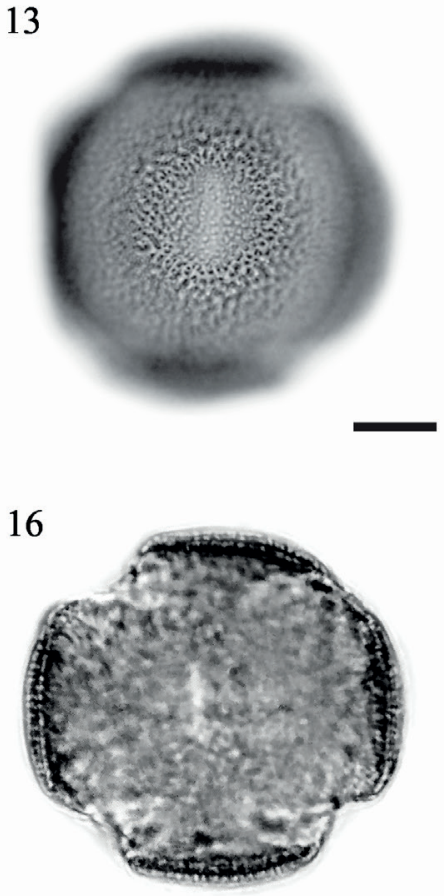

19

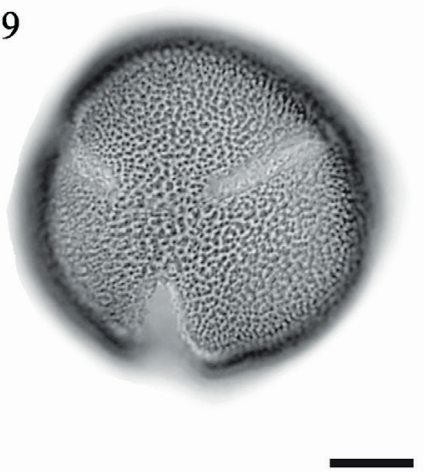

22

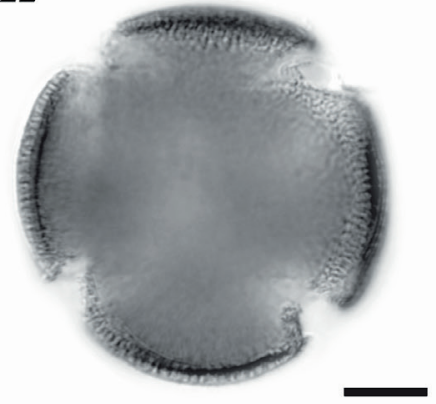

14

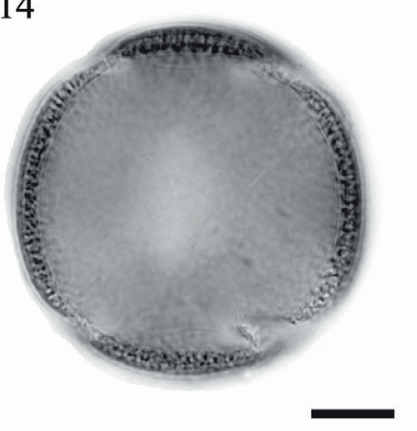

17

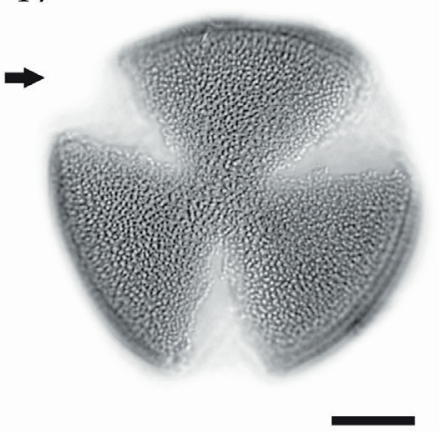

20

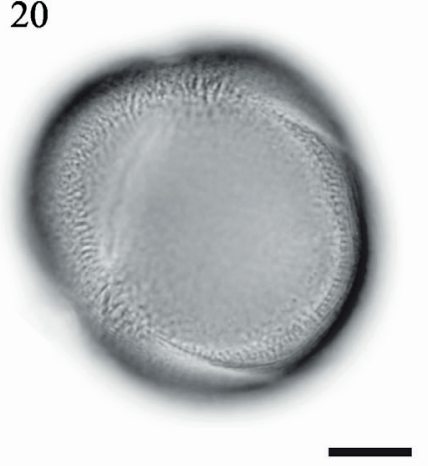

23

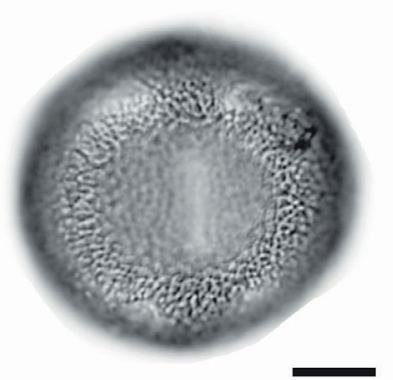

15

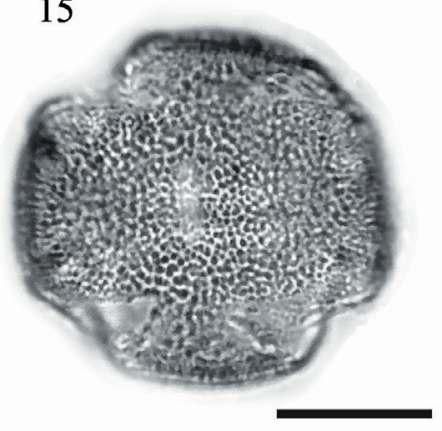

18

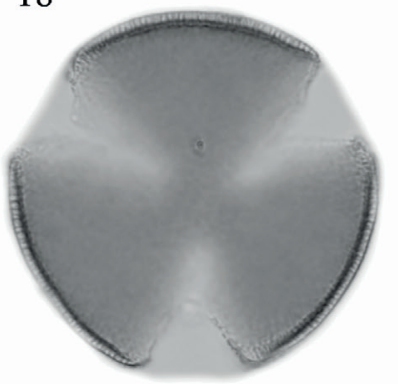

21

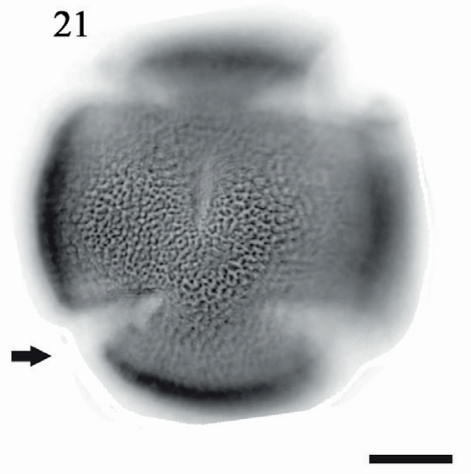

24

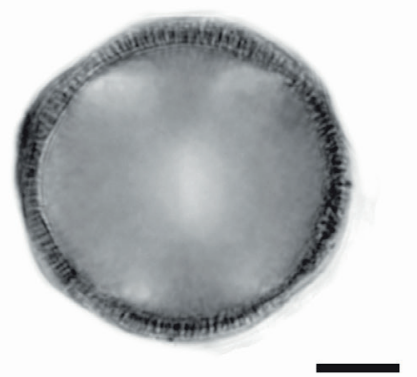

Figs. 13-24. Fotomicrografias de grãos de pólen da família Cactaceae. 13, 14 L. warmingianum. 13. vista equatorial com detalhe da abertura e superfície da exina; 14. corte óptico evidenciando a espessura da exina e columelas; 15, 16 Rhipsalis campos-portoana. 15. vista equatorial com detalhe da abertura e superfície da exina; 16. vista em plano transversal; 17, 18. $R$. cereuscula. 17. vista polar evidenciando o tipo de abertura e detalhe da exina, grão de pólen danificado pelo processo acetolítico, mostrando a fragilidade das espécies ao método (vide seta); 18. corte óptico evidenciando a espessura da exina e columelas); 19, 20 R. floccosa. 19. vista polar mostrando o apocolpo; 20. vista em plano transversal; 21, 22 $R$. paradoxa. 21. vista equatorial com detalhe da abertura e superfície da exina, grão de pólen danificado pelo processo acetolítico, mostrando a fragilidade das espécies ao método (vide seta); 22. corte óptico evidenciando a espessura da exina e columelas; 23, $24 R$. teres. 23. vista equatorial, detalhe do colpo e posicionamento das aberturas; 24. corte óptico evidenciando a espessura da exina e columelas. Barras $=20 \mu \mathrm{m}$. 

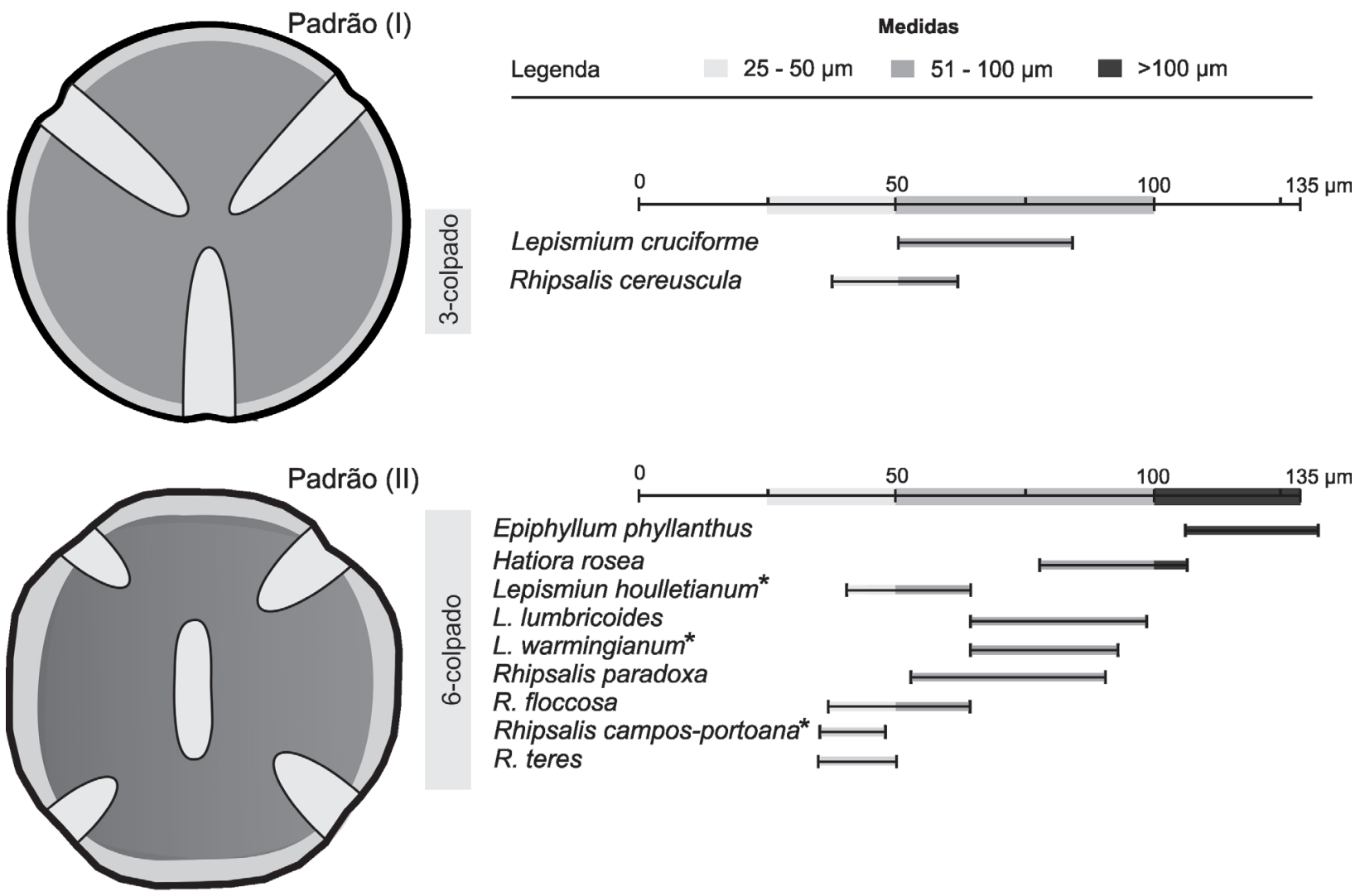

Fig. 25. Desenho esquemático representando os dois padrões morfológicos de grãos de pólen de espécies de cactáceas com hábito epífito do Rio Grande do Sul reconhecidos: (I) grão de pólen 3-colpados, (II) grãos de pólen 6-colpados, e a relação das medidas para cada espécie (* espécies que ocorrem em baixa frequência na forma 3-colpados). Escala $=135 \mu \mathrm{m}$.

Tabela 1. Medidas $(\mathrm{em} \mu \mathrm{m})$ das espécies de Cactaceae epifíticas ocorrentes no Rio Grande do Sul, onde: $\mathrm{P}=$ eixo polar, $\mathrm{E}=$ eixo equatorial, Ex = exina, Orn = ornamentação, acompanhadas do número de colpos, medidas dos colpos (eixo maior e menor), relação P/E.

\begin{tabular}{|c|c|c|c|c|c|c|c|c|}
\hline Espécies & $\mathrm{P}$ & $\mathrm{E}$ & Ex & Orn & $\mathrm{n}^{\circ}$ de colpos & Eixo maior & Eixo menor & $\mathrm{P} / \mathrm{E}$ \\
\hline Epiphyllum phyllanthus & $\begin{array}{c}101 \\
(134) 167\end{array}$ & $88(123) 150$ & $2(2,7) 3$ & $2(2,5) 3$ & 6 & $28(30) 35$ & $2(4) 6$ & 1,08 \\
\hline Hatiora rosea & $77(92) 115$ & $70(88) 105$ & $3(4) 5$ & $<1$ & 6 & $16(20) 22$ & $3(4) 5$ & 1,04 \\
\hline Lepismium cruciforme & $59(70) 81$ & $50(69) 75$ & $2(2,4) 3$ & $<1$ & 3 & $35(40) 45$ & $6(8) 10$ & 1,01 \\
\hline L. houlletianum & $47(51) 60$ & $44(49) 55$ & $2,5(3,5) 4$ & $<1$ & (3) 6 & $18(20) 25$ & 1,5 (2) 2,5 & 1,04 \\
\hline L. lumbricoides & $65(76,5) 87$ & $64(72,5) 85$ & $2(3,2) 5$ & $<1$ & 6 & $15(20) 25$ & $6(10) 12$ & 1,05 \\
\hline L. warmingianum & $61(78,4) 95$ & $57(74,4) 85$ & $1,5(2) 2,5$ & $<1$ & (3) 6 & $16(18) 20$ & $2(3) 4$ & 1,05 \\
\hline Rhipsalis campos-portoana & $30(35) 42$ & $28(32,8) 40$ & $1(1,2) 2$ & $<1$ & (3) 6 & $10(12) 13$ & $4(6) 8$ & 1,09 \\
\hline R. cereuscula & $42(54) 63$ & 34 (42) 53 & $1(1,7) 2$ & $<1$ & 3 & $18(20) 22$ & $2(3) 4$ & 1,28 \\
\hline R. floccosa & $51(56) 62$ & $37(42) 46$ & $1(1,2) 1,5$ & $<1$ & 6 & 25 (28) 30 & 2 (4) 6 & 1,33 \\
\hline R. paradoxa & $52(69) 85$ & 50 (64) 82 & $2,5(3,2) 4$ & $<1$ & 6 & $8(10) 12$ & $2(2,5) 3$ & 1,07 \\
\hline R.teres & $38(45) 55$ & $35(41) 46$ & $1(1,4) 1,5$ & $<1$ & 6 & $10(14) 16$ & $2(4) 6$ & 1,09 \\
\hline
\end{tabular}

de pólen 3-colpados, perfurados, espiculados a espinhosos, Harrisia adscendens (Gürke) Britton \& Rose, Cereus alhicaulis (Britton \& Rose) Liitzelburg, C.jamacaru DC., Pilosocereus catingicola (Gürke) Byles \& G.D. Rowley, $P$. chrysostele (Vaupel) Byles \& G.D. Rowley, P. glaucochrous (Werderm.) Blyles \& G.D. Rowley, P. pachycladus F. Ritter, P. tuberculatus (Werderm.) Byles \& G.D. Rowley, Stephanocereus luetzelburgii (Vaupel) N. P. Taylor \& Eggli, Arrojadoa rhodantha Britton \& Rose e Facheiroa squamosa (Gürke) P.J. Braun \& Esteves; (2) grãos de pólen pantocolpados, perfurados, espiculosos, Pereskia stenantha F. Ritter, Melocactus bahiensis Luetzelb., M. ernestii Vaupel e M. zehntneri (Britton \& Rose) Luetzelb.; (3) grãos de pólen pantocolpados, perfurados, psilados a granulados, Opuntia cochenillifera DC. e O.palmadora Britton \& Rose; (4) grãos de pólen pantoporados, perfurados, psilados $O$. inamoena K. Schum.; (5) grãos de pólen pantoporados, foveolados a reticulados, granulados, O. ficus-indica. Adicionalmente, também identificaram grãos de pólen considerados "anormais", apresentando polimorfismo intrae interespecífico no número de aberturas (principalmente em Melocactus Link \& Otto).

$\mathrm{Na}$ região sul do Brasil, 15 espécies de cactáceas terrícolas (não epífitas) foram descritas palinologicamente 
por Schlindwein (1995), sendo separadas em dois grandes grupos com base na morfologia das aberturas: (I) grãos de pólen colpados (3-zonocolpados: Echinopsis oxygona (Link) Zucc. ex Pfeiff., Gymnocalycium denudatum Pfeiff. ex C.F. Först., Notocactus neohorstii S. Theun., N. polyacanthus (Link \& Otto) S. Theun., N. sellowii (Link \& Otto) S. Theun., N. sucineus F. Ritter, N. uebelmannianus Buining; 6 a 9-colpados: Frailea phaeodisca (Speg.) Backeb. \& F.M. Knuth; 10 a 12-colpados: Frailea pigmaea K.H. Prestlé; e, (II) grãos de pólen porados (10 a 15-porados: Opuntia monacantha Haw.; 12 a 18-porados: O. paraguayensis K. Schum., O. viridirubra (F. Ritter) C. Schlindwein; 15 a 35-porados: O. brunneogemmia (F. Ritter) C. Schlindwein). Dentre esses, destacam-se Notocactus mammulosus (Lem.) A. Berger, que apresenta acentuado heteromorfismo quanto ao número de aberturas, com grãos de pólen irregulares, 6 a 7-colpados e 3-zonocolpados, e Notocactus ottonis (Lehm.) A. Berger, que apresenta 3-zonocolpados a 6-colpados. Bauermann et al. (2013) descreveram grãos de pólen de Opuntia ficus-indica como muito grandes, exina reticuladoheterobrocada e aberturas pantoporadas.

Em alguns estudos, grãos de pólen 3-colpados e 6-colpados são apresentados com rompimento desta membrana, característica verificada também nas fotomicrografias apresentadas por Cuadrado \& Garralla (2009: figs. 1 D-G) e Lattar \& Cuadrado (2010: figs. 1 K-N).

Leuenberger (1976) relaciona o heteromorfismo e a evolução na forma apertural das Cactaceae a outras famílias botânicas. O padrão estenopalinológico da primeira, incluindo forma e tipo de aberturas, é compartilhado evolutivamente com grãos de pólen das famílias Acanthaceae, Leguminosae e Rubiaceae (Santos \& Pin-Ferreira 2001). O heteromorfismo constatado por Leuenberger (1976) no número de aberturas também foi identificado neste trabalho. Ocorrem em baixa frequência grãos de pólen com aberturas do tipo 3-colpados em Lepismium houlletianum, L. warmingianum e Rhipsalis campos-portoana, que apresentaram grãos de pólen preferencialmente 6-colpados, característica bem acentuada nas espécies de cactáceas, sobretudo nos gêneros Opuntia e Melocactus (Santos \& Pin-Ferreira 2001), de hábito não epífito.

Os diferentes padrões descritos para espécies argentinas (Cuadrado \& Garralla 2009; Lattar \& Cuadrado 2010), norte do Chile (Miesen et al. 2015), bem como espécies do nordeste (Santos et al. 1997; Santos \& Pin-Ferreira 2001) e sul do Brasil (Schlindwein 1995) revelam grãos de pólen morfologicamente relacionados aos dois padrões morfológicos aqui descritos, com variações no tamanho dos grãos de pólen, textura da exina, forma e, principalmente, tipo de aberturas (colpados, zonocolpados, porados e pantoporados), confirmando as observações quanto ao heteromorfismo da família descrito por Leuenberger (1976).

Os padrões morfológicos poderão ser utilizados no reconhecimento de grãos de pólen dispersos da família cactácea em análises de chuva polínica, sedimentos superficiais e depósitos sedimentares, tais como turfeiras, onde são comumente realizados estudos palinológicos, dando subsídios às interpretações paleoambientais e paleoclimáticas. A identificação dos padrões morfológicos I e II, além de refinar as interpretações quando associados a outros indicadores polínicos, pode indicar proximidade ou estabelecimentos de determinada vegetação.

\section{AGRADECIMENTOS}

Os autores agradecem ao Herbário do Instituto de Biociências da Universidade Federal do Rio Grande do Sul pela cessão de material para recuperação dos grãos de pólen.

\section{REFERÊNCIAS}

Barth, O.M. \& Melhem, T.S. 1988. Glossário Ilustrado de Palinologia. Universidade Estadual de Campinas, Campinas. 77 p.

Barthlott, W. 1983. Biogeography and evolution in neo- and paleotropical Rhipsalinae (Cactaceae). Verhandlungen des Naturwissenschaftlichen Vereins in Hamburg 7:241-248.

Barthlott, W. \& Hunt, D.R. 1993. Cactaceae. In The families and genera of vascular plants (K. Kubitzki, J.G. Rohwer \& V. Bittrich, eds.). Springer Verlag, Berlin. p. 161-197.

Barthlott, W. \& Taylor, N.P. 1995. Notes towards a monograph of Rhipsalideae (Cactaceae). Bradleya 13:43-79.

Bauer, D. \& Waechter, J.L. 2006. Sinopse taxonômica de Cactaceae epifíticas no Rio Grande do Sul, Brasil. Acta Botanica Brasilica 20:225-239.

Bauermann, S.G., Radaeski, J.N., Evaldt, A.C.P., Queiroz, E.P. Mourelle, D., Prietro, A. \& Silva, C.I. 2013. Pólen nas Angiospermas diversidade e evolução. Editora da Universidade Luterana do Brasil, Canoas. $216 \mathrm{p}$.

Brack, P., Bueno, R.M., Falkenberg, D.B., Paiva, M.R.C., Sobral, M. \& Stehmann, J.R. 1985. Levantamento florístico do Parque Estadual do Turvo, Tenente Portela, Rio Grande do Sul, Brasil. Roessléria 7(1):69-94.

Carneiro, A.M., Farias-Singer, R., Ramos, R.A. \& Nilson, A.D. 2016. Cactos do Rio Grande do Sul. Fundação Zoobotânica, Porto Alegre. $224 \mathrm{p}$.

Cuadrado, G.A. \& Garralla, S.S. 2009. Palinología de los géneros de Cactaceae Maihuenia (Maihuenioideae) y Pereskia (Pereskioideae) de Argentina. Bonplandia 18(1):5-12.

Erdtman, G. 1952. Pollen morphology and plant taxonomy-Angiosperms. Almqvisit \& Wiksell, Stockholm. 539 p.

Freitas, M.F. 1992. Cactaceae da Área de Proteção Ambiental da Massambaba, Rio de Janeiro, Brasil. Rodriguésia 42/44:67-91.

Geraldino, H.C.L., Caxambú, M.C. \& Souza, D.C. 2010. Composição florística e estrutura da comunidade de epífitas vasculares em uma área de ecótono em Campo Mourão, PR, Brasil. Acta Botanica Brasilica 24(2):469-482.

Giongo, C. \& Waechter, J.L. 2004. Composição florística e estrutura comunitária de epífitos vasculares em uma floresta de galeria na Depressão Central do Rio Grande do Sul. Revista Brasileira de Botânica 27(3):563-572.

Gonçalves, C.N. \& Waechter, J.L. 2003. Aspectos florísticos e ecológicos de epífitos vasculares sobre figueiras isoladas no norte da planície costeira, RS. Acta Botanica Brasilica 17(1):1-17.

Kimnach, M. 1964. Epiphyllum phyllanthus. Cactus and Succulent Journal 36:105-115.

Lattar, E. \& Cuadrado, G. 2010. Estudios palinologicos de espécies argentinas de los generos Cereus, Cleistocactus, Denmoza, Echinopsis y Monvillea (Cactaceae, Cactoideae). Boletín de la Sociedad Argentina de Botánica 45:93-107

Leuenberger, B.E. 1976. Die Pollenmorphologie der Cactaceae. Dissertationes Botanicae 31:1-321.

Loefgren, A. 1915. O gênero Rhipsalis. Archivos do Jardim Botânico do Rio de Janeiro 1:61-104. 
1917. Novas contribuições para o gênero Rhipsalis. Archivos do Jardim Botânico do Rio de Janeiro 2:34-45.

Lombardi, J.A. 1991. O gênero Rhipsalis Gärtner (Cactaceae) no Estado de São Paulo I. Espécies com ramos cilíndricos ou subcilíndricos. Acta Botanica Brasilica 5(2):53-76.

1995. O gênero Rhipsalis Gärtner (Cactaceae) no Estado de São Paulo II. Espécies com ramos aplanados. Acta Botanica Brasilica 9(1):151-161.

Miesen, F., de Porras, M.E. \& Maldonado, A. 2015. Pollen morphology of Cactaceae in Northern Chile. Gayana Botánica 72(2):258-271.

Nowicke, J.W. 1975. Pollen morphology in the order Centrospermae. Grana 15:51-77.

Nowicke, J.W. \& Skvarla, J.J.1979. Pollen Morphology: the potential influence in higher order systematic. Annals of the Missouri Botanical Garden 66:633-700.

Punt, W., Blackmore, S., Nilsson, S., Thomas, A. 2007. Glossary of pollen and spore terminology. Review of Palaeobotany and Palynology 143:1-81.

Rambo, B. 1951. A imigração da selva higrófila no Rio Grande do Sul. Anais Botânicos do Herbário Barbosa Rodrigues 3(3):55-91. . 1954a. Análise histórica da flora de Porto Alegre. Sellowia 6:9-112. . 1954b. História da flora do litoral riograndense. Sellowia 6:113172.

. 1956a. Der Regenwald am oberen Uruguay. Anais Botânicos do Herbário Barbosa Rodrigues 7:183-233.

1956b. A flora fanerogâmica dos Aparados riograndenses. Anais Botânicos do Herbário Barbosa Rodrigues 7:235-298.

1961. Migration routes of the South Brazilian rain forest. Pesquisas, série Botânica 5(12):1-54.
Ritter, F. 1979. Kakteen in Südamerika. v.1. Friedrich Ritter, Spangenberg. p. $19-240$.

Rogalski, J.M. \& Zanin, E.M. 2003. Composição florística de epífitos vasculares no estreito de Augusto César, Floresta Estacional Decidual do Alto Uruguai, RS, Brasil. Revista Brasileira de Botânica 26(4):551556.

Salgado-Labouriau, M.L. 1973. Contribuição à palinologia dos cerrados. Academia Brasileira de Ciências, Rio de Janeiro. 285p.

Santos, F.A.R. \& Pin-Ferreira, A.B. 2001. Variabiliadade olínica de Opuntia Brasiliensis (Willd.) Haw. (Cactaceae). Sitientibus série Ciências Biológicas 1(2):95-98.

Santos, F.A.R., Watanabe, M \& Alves, J.L.H. 1997. Pollen morphology of some Cactaceae of North-Eastern Brazil. Braleya 15:84-97.

Scheinvar, L. 1985. Cactáceas. In Flora Ilustrada Catarinense. Fascículo Cactáceas. Herbário Barbosa Rodrigues. Itajaí. p. 1-183.

Schlindwein, C. 1995. Melittophilous plants, their pollen and flower visiting bees in southern Brazil. 2. Cactaceae. Biociências 3(2):35-71.

Souza, P.A., Felix, C.M. \& Cancelli, R.R. 2009. Laboratório de Palinologia Marleni Marques Toigo, Instituto de Geociências da Universidade Federal do Rio Grande do Sul. Boletín de la Asociación Latinoamericana de Paleobotánica y Palinología 13:163-176.

The International Plant Name Index. 2016. Disponível em: $<$ http:// www.inpi.org.> Acessado em 30.06.2016.

Waechter, J.L. 1986. Epífitos vasculares da mata paludosa do Faxinal, Torres, Rio Grande do Sul, Brasil. Iheringia. Série Botânica 34:39-49. . 1998. Epifitismo vascular em uma floresta de restinga do Brasil subtropical. Ciência e Natura 20:29-42. 